\title{
Flesh by design
}

\author{
Treating living matter as a material has immense biomedical potential, but it's worth acknowledging how the notion \\ unsettles longstanding preconceptions and raises challenging new questions.
}

B ioprinting tissues and organs for medical implantation is making steady progress towards the point of clinical use. L'Oréal is investing in it to make synthetic skin for testing cosmetics, and several start-up companies are exploring $3 \mathrm{D}$ printing to create organs from scratch.

The artificial construction of tissues from living cells represents one of the most striking mergers of materials science and biotechnology: a realization, perhaps, of the biologist Jacques Loeb's aspiration, voiced in 1890 , to "succeed in a technology of living substance."

We have become blind now to the strangeness of that vision. Importing the language of printing technology, with its inkjet write heads and 'inks' (here typically tiny clusters of living cells in a biodegradable gel wrapper), renders familiar what is in fact profoundly disorientating. Loeb began that lexical elision when he spoke of biology in terms of engineering - a tradition continued now in the realm of synthetic biology, with its gene circuits, switches, amplifiers and 'registries of standard parts'. Such terminology is useful for suggesting how existing conceptual frameworks can help us to assimilate new ideas. But sometimes it's good to keep in sight what is in fact conceptually novel, disruptive and strange.

Regarding living matter as a kind of material amenable to synthesis and design was a revolutionary concept. Before the twentieth century, the material substance of organisms was either nourished by an individual organism or it was dead (or dying). That changed in 1907 when the embryologist Ross Harrison showed that he could sustain pieces of amphibian embryonic tissue in vitro. Not only did they survive but they would grow and differentiate into nerves.

For Harrison this was all in the service of resolving a controversy about neurogenesis. But the surgeon Alexis Carrel recognized that the process of tissue culture was transformative in its own right, asserting an autonomy of living matter independent from the parent body. Life of the material was no longer reliant on life of the individual. In 1910 Carrel, working with pathologist Montrose Burrows at the Rockefeller Institute in New York, reported that he could culture chicken heart tissue and even - in a demonstration symbolic of life itself - keep it in a pulsatile state. Carrel claimed that this tissue was 'immortal', although the later discovery of the Hayflick limit on cell division implied that some accidental or deliberate manipulation must have been involved in maintaining the culture until shortly after Carrel's death in 1944.

This, then, was indeed a 'technology of living substance', and it was unsettling for long-held preconceptions about life. Carrel's work was described in one newspaper report as having the "creeping horror of the most morbid narrative of Edgar Allan Poe, with the additional shiver that it is the truth and not the produce of a fantastic imagination."

Perhaps that looks like extravagant hyperbole today, when tissue culture has become routine and the growth of stem cells - or the reprogramming of mature somatic cells to a pluripotent state ${ }^{2}-$ has raised the prospect of in vitro growth of organs for transplantation. Traditional materials science plays a central role in such efforts, among other things as a source of biodegradable polymer scaffolds for supporting and shaping cell growth.

While the real potential of these advances for biomedicine remains largely to be determined, they are fast approaching clinical relevance, especially for twodimensional and hollow tissues ${ }^{3-5}$. The use of induced pluripotent stem cells in such technologies, made from differentiated adult cells, raises the prospect of making tissues and organs that do not suffer from problems of immune rejection, although some safety issues remain to be addressed, not least questions about the extent of their reprogramming and their potential to turn tumorigenic in vivo. But that aside, it is hard now to see anything 'morbid' or 'creepy' in these techniques for repairing and replacing malfunctioning organs. And the capacity of cells for spontaneous differentiation and self-organization suggests that bioprinting of complex tissues may not need to do much more than sketch the outlines - the cells will fill in fine details themselves.

Still, it might be wise not to become too anaesthetized to the ethical and even philosophical challenges of a technology of living matter. Already the possibilities seem to be falling off the edge of a moral map for evaluating them. Frankenstein-like talk of bioprinting humans is more rhetorical than a statement of intent - and in any case the image is actually more aligned with Karel Čapek's 1920 play R.U.R. in which 'robots' (Čapek introduced the word) are

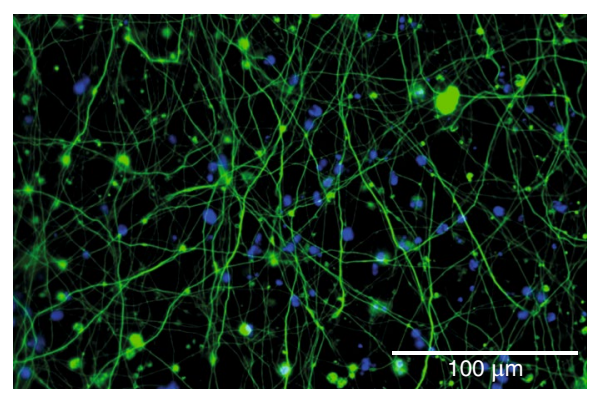

Neurons grown from induced stem cells.

Credit: Chris Lovejoy and Selina Wray, UCL

manufactured from fleshy, organic dough as if on a factory production line. But among the 'living material' that stem-cell technologies now provide are structures called embryoids or 'synthetic human entities with embryo-like features' (SHEEFs) ${ }^{6}$, a term that could come straight out of science fiction. Even if they have no potential to develop into people, we do not yet know what moral status to give these entities within the framework of embryo-research regulation.

Similar considerations apply to human brain organoids: organized (albeit not truly brain-like) structures containing networks of active neurons, which can also be cultured from induced stem cells (pictured). Even the most recent discussion of their ethical status has already been complicated by claims that these organoids can be given a vascular structure $^{8,9}$, opening up the possibility of growing them larger than the current size of a lentil - and forcing us to confront at least the hypothetical question of whether they could support some form of self-awareness.

In such ways, a technology of living material has not diminished in its strangeness or its ethical quandaries over the past hundred years.

Published online: 23 August 2018 https://doi.org/10.1038/s41563-018-0156-8

\footnotetext{
References

1. Landecker, H. Culturing Life 92. (Harvard University Press, Cambridge, MA, 2007).

2. Takahashi, K. \& Yamanaka, S. Cell 126, 663-676 (2006).

3. Mehrban, N., Teoh, G. Z. \& Birchall, M. A. Int. J. Bioprinting 2 , 6-19 (2016).

4. Murphy, S. V. \& Atala, A. Nat. Biotechnol. 32, 773-785 (2014).

5. Kang, H.-W. et al. Nat. Biotechnol. 34, 312-319 (2016).

6. Aach, J., Lunshof, J., Iyer, E. \& Church, G. M. eLife 6, e20674 (2017).

7. Farahany, N. A. et al. Nature 556, 429-432 (2018).

. Pham, M. T. et al. Neuroreport 29, 588-593 (2018).

Mansour, A. A. et al. Nat. Biotechnol. 36, 432-441 (2018).
} 